\title{
Use of the Apollo detachable-tip microcatheter for endovascular embolization of arteriovenous malformations and arteriovenous fistulas
}

\author{
Bruno C. Flores, MD, ${ }^{1}$ Alfred P. See, MD, ${ }^{1}$ Gregory M. Weiner, MD, ${ }^{2}$ Brian T. Jankowitz, MD, ${ }^{2}$ \\ Andrew F. Ducruet, MD, ${ }^{1}$ and Felipe C. Albuquerque, MD' ${ }^{1}$ \\ 1'Department of Neurosurgery, Barrow Neurological Institute, St. Joseph's Hospital and Medical Center, Phoenix, Arizona; and \\ 2Department of Neurological Surgery, University of Pittsburgh Medical Center, Pittsburgh, Pennsylvania
}

\begin{abstract}
OBJECTIVE Liquid embolic agents have revolutionized endovascular management of arteriovenous malformations (AVMs) and arteriovenous fistulas (AVFs). Nonetheless, since 2005, the US FDA has received more than 100 reports of microcatheter breakage or entrapment related to Onyx embolization, including 9 deaths. In 2014, the Apollo detachabletip microcatheter became the first of its kind available in the US. Since then, few reports on its safety have been published.

METHODS The authors conducted a retrospective review of endovascular cases by searching the patient databases at 2 tertiary cerebrovascular centers (Barrow Neurological Institute and University of Pittsburgh Medical Center). Patients who underwent endovascular embolization of an AVM or AVF using the Apollo microcatheter were identified. Patient demographics and lesion characteristics were collected. The authors analyzed Apollo-specific endovascular variables, such as number of microcatheterizations, sessions, and pedicles embolized; microcatheter tip detachment status; obliteration rate; and endovascular- and microcatheter-related morbidity and mortality.
\end{abstract}

RESULTS From July 2014 to October 2016, a total of 177 embolizations using the Apollo microcatheter were performed in 61 patients (mean age 40.3 years). The most frequent presentation was hemorrhage (22/61, 36.1\%). Most lesions were AVMs (51/61, 83.6\%; mean diameter $30.6 \mathrm{~mm})$. The mean Spetzler-Martin grade was 2.4. Thirty-nine (76.5\%) of 51 patients with AVMs underwent resection. Microcatheterization was successful in 172 pedicles. Most patients (50/61, 82\%) underwent a single embolization session. The mean number of pedicles per session was 2.5 (range 1-7). Onyx-18 was used in 103 (59.9\%), N-butyl cyanoacrylate (NBCA) in 44 (25.6\%), and Onyx-34 in 25 (14.5\%) of the 172 embolizations. In $45.9 \%$ (28/61) of the patients, lesion obliteration of $75 \%$ or greater was achieved. Tip detachment occurred in $19.2 \%$ (33/172) of microcatheters. Fifty-three (86.9\%) of the 61 patients who underwent embolization with the Apollo microcatheter had good functional outcomes (modified Rankin Scale score 0-2). No unintended microcatheter fractures or related morbidity was observed. One patient died of intraprocedural complications unrelated to microcatheter selection. In the univariate analysis, microcatheter tip detachment $(p=0.12)$, single embolized pedicles $(p=0.12)$, and smaller AVM nidus diameter $(p=0.17)$ correlated positively with high obliteration rates $(>90 \%)$. In the multivariate analysis, microcatheter tip detachment was the only independent variable associated with high obliteration rates (OR 9.5; $p=0.03$ ).

CONCLUSIONS The use of the Apollo detachable-tip microcatheter for embolization of AVMs and AVFs is associated with high rates of successful catheterization and obliteration and low rates of morbidity and mortality. The microcatheter was retrieved in all cases, even after prolonged injections in distal branch pedicles, often with significant reflux. This study represents the largest case series on the application of the Apollo microcatheter for neurointerventional procedures.

https://thejns.org/doi/abs/10.3171/2017.9.JNS17397

KEY WORDS Apollo microcatheter; arteriovenous fistula; arteriovenous malformation; detachable-tip microcatheter; embolization; vascular disorders; interventional neurosurgery; oncology

ABBREVIATIONS AVF = arteriovenous fistula; $\mathrm{AVM}=$ arteriovenous malformation; $\mathrm{DMSO}=$ dimethyl sulfoxide; $\mathrm{EVOH}=$ ethylene vinyl alcohol; $\mathrm{NBCA}=\mathrm{N}$-butyl cyanoacrylate. SUBMITTED February 14, 2017. ACCEPTED September 11, 2017.

INCLUDE WHEN CITING Published online March 23, 2018; DOI: 10.3171/2017.9.JNS17397. 


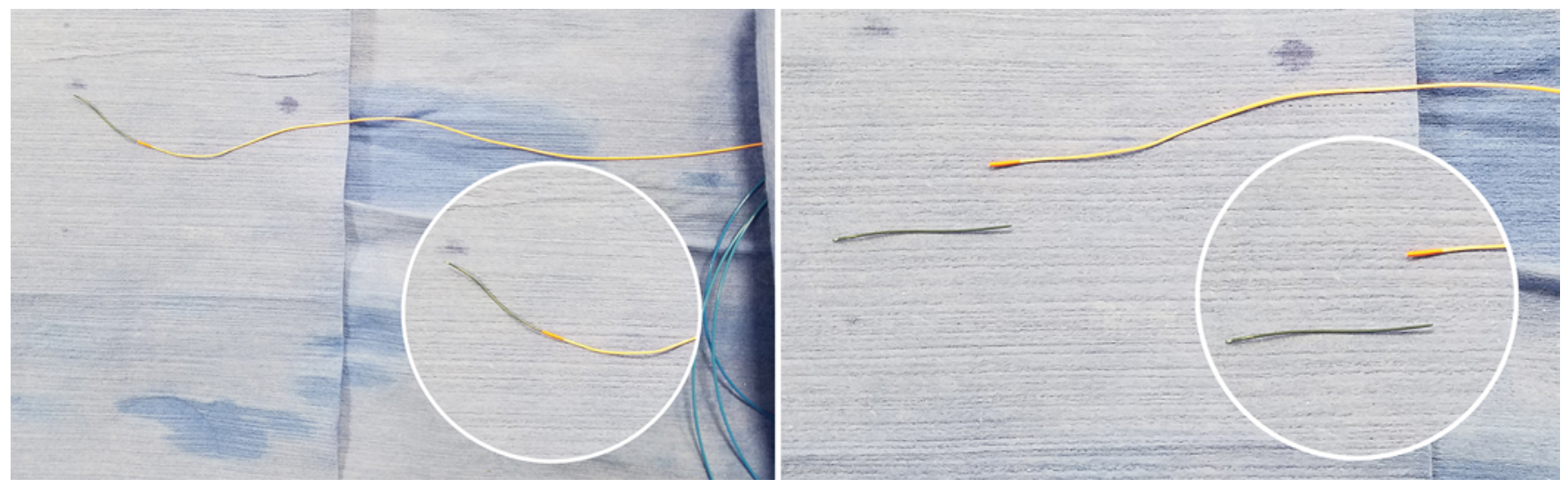

FIG. 1. Left: Intact Apollo microcatheter with 2 distinct components: the primary catheter and the detachable tip. The orange segment contains a radiopaque proximal marker within it, and the gray detachable segment contains a second distal radiopaque marker at the tip. The separation point is approximately midway along the orange segment and is immediately distal to the radiopaque marker. Right: Apollo microcatheter showing a detached tip. Figure is available in color online only.

$\mathrm{T}$ HE development of $N$-butyl cyanoacrylate (NBCA; Trufill NBCA liquid embolic system, DePuy Synthes) and ethylene vinyl alcohol (EVOH; Onyx liquid embolic system, Covidien/Medtronic) liquid embolysates has revolutionized the endovascular management of arteriovenous malformations (AVMs) and arteriovenous fistulas (AVFs). Trufill and Onyx were approved by the US FDA in September 2000 and July 2005, respectively, for preoperative embolization of brain AVMs. Disadvantages associated with the use of cyanoacrylates for the embolization of AVMs include their rapid polymerization, steep operator learning curve, unpredictable embolization pattern, and the frequent occurrence of microcatheter entrapment or the need for intraprocedural microcatheter exchange. The nonadhesive properties of EVOH have overcome some of the disadvantages encountered with the use of cyanoacrylates. Nonetheless, in 2012 the FDA issued a safety communication alert for the potential risks of catheter entrapment also associated with the use of Onyx. Since 2005, more than 100 cases of catheter breakage or entrapment have been reported to the FDA, including 9 deaths. ${ }^{35}$ In at least 54 of those cases, the microcatheter could not be retrieved.

In 2006, the Sonic flow-directed, braided microcatheter (Balt Extrusion) became the first detachable-tip microcatheter to be approved for Onyx embolization of AVMs. ${ }^{4,20,22,33,34,36}$ The Sonic microcatheter, however, has not been approved by the FDA for the US market. In May 2014, the Apollo detachable-tip microcatheter (Covidien/ Medtronic; Fig. 1) became the first detachable-tip microcatheter to receive FDA approval for embolization of brain AVMs using the Onyx liquid embolic system in the US. This microcatheter has been successfully used off-label for the embolization of AVFs, vein of Galen malformations, and hypervascular tumors. ${ }^{2,12,13,15,24,31}$ A few authors have reported their initial experience with its concomitant use with NBCA.,24 However, the neurointerventional literature has consisted mainly of small, single-institution case series or case reports. An ongoing postmarket safety study designed as a prospective registry (clinical trial no. NCT02378883, ClinicalTrials.gov) is currently in the en- rollment phase at 24 centers in the US, but the study's preliminary results are currently unpublished.

In this study, we retrospectively reviewed the utility of the Apollo detachable-tip microcatheter for endovascular embolization of AVMs and AVFs. Special attention was focused on applications of the microcatheter, its safety profile, and technical implications for its use in neurointerventionalist practice. We also review the literature related to published case series on the use of the Sonic or Apollo microcatheter.

\section{Methods}

A retrospective review was conducted using 2 independent, prospectively collected endovascular patient databases from 2 high-volume, tertiary cerebrovascular referral centers (Barrow Neurological Institute and the University of Pittsburgh Medical Center). Institutional review board approval was obtained independently from both study sites.

The medical charts of all patients treated endovascularly for an intracranial AVM or AVF from July 2014 to October 2016 were analyzed. Operative reports and treatment angiographic studies were reviewed, and patients in whom at least one Apollo detachable microcatheter was used were identified $(n=61)$. Demographics and characteristics were collected for patients and lesions, including patient age and sex, clinical presentation, lesion location and size, Spetzler-Martin AVM grade, presence of perinidal or intranidal aneurysms, and adjuvant treatment (either resection or stereotactic radiosurgery). In addition, descriptive endovascular variables related to the use of the Apollo microcatheter were reviewed, such as number of catheterized pedicles and embolization sessions, type of liquid embolic agent used, endovascular angiographic obliteration, and microcatheter detachment tip status. Endovascular- and Apollo-related morbidity and mortality rates were calculated. Functional outcome at last followup was determined using the modified Rankin Scale?

The detachment status of the microcatheter tip after embolization was determined using 2 methods: review of 
the operative report and direct review of follow-up angiographic images. Cases in which the operative report clearly stated the detachment status of the microcatheter after retrieval or those in which a definite detached tip could be identified or excluded on the postembolization control angiogram were defined as positive detachment or negative detachment. Cases were defined as undetermined if the detachment status information was missing from the operative report or if the microcatheter tip could not be accurately identified on the postembolization images by 3 independent reviewers (B.C.F., A.P.S., and G.M.W.).

Continuous variables are reported as mean, median, and standard deviation, as applicable. Categorical and continuous variables were collected for all patients described above, independent of microcatheter tip detachment status. The correlations between detachment status of the Apollo tip and several dependent variables were analyzed using openly available statistical software ( $R$, version 3.0; R Project for Statistical Computing Free Software Foundation, Inc.). The obliteration rate was categorized as $\leq$ $90 \%$ or $>90 \%$. The diameter of the AVM and the number of embolization sessions were assessed in a continuous fashion; the number of pedicles was categorized as $\geq 1$. The association between detachment and continuous dependent variables was performed using generalized linear models applying the glm function in R (version 3.0) with methods as implemented in the R Project for Statistical Computing. The association between detachment and the categorical percentage of obliteration was assessed using Fisher's exact test as implemented in the R Project for Statistical Computing. On univariate analysis, variables with values of $\mathrm{p}<0.2$ were selected for inclusion in the multivariate model. Multivariate analysis was completed with the generalized linear model applying the glm function. A p value $<0.05$ was defined for statistical significance.

Finally, a Medline/PubMed literature search was conducted using the terms "detachable tip microcatheter," "Sonic microcatheter," and "Apollo microcatheter." Retrieved studies were then analyzed, and lesion type, number of embolized pedicles, microcatheter used, tip detachment status, and Apollo/Sonic-specific morbidity and mortality rates were recorded.

\section{Results}

From July 2014 to October 2016, a total of 61 patients met inclusion criteria. The mean patient age was $40.3 \pm$ 18.1 years, with a slight female predominance $(55.7 \%$ female vs $44.3 \%$ male). Most of the 61 patients presented with hemorrhage (22 patients [36.1\%]), headaches (14 [23\%]), or seizures (13 [21.3\%]). AVMs were diagnosed in $51(83.6 \%)$ of the 61 patients and were predominantly located in the frontal (15 [29.4\%]) or temporal (13 [25.5\%]) lobes. The mean AVM size was $30.6 \pm 13.2 \mathrm{~mm}$, with a mean Spetzler-Martin grade of $2.4 \pm 0.9$. The prevalence of AVM-associated intracranial aneurysms (11/51 [21.6\%]) was similar to that in other reports. ${ }^{9}$ Thirty-nine $(76.5 \%)$ of the 51 AVM patients underwent postembolization resection (Table 1).

Catheterization using the Apollo microcatheter was attempted in 177 of 210 pedicles in 61 patients, with a high
TABLE 1. Descriptive analysis and demographics of 61 patients treated by endovascular embolization of AVMs or AVFs using the Apollo microcatheter

\begin{tabular}{|c|c|}
\hline Variable & Value \\
\hline Age, mean $\pm S D$ (range) in yrs & $40.3 \pm 18.1(10-80)$ \\
\hline \multicolumn{2}{|l|}{ Sex } \\
\hline Female & $34(55.7)$ \\
\hline Male & $27(44.3)$ \\
\hline \multicolumn{2}{|l|}{ Clinical presentation* } \\
\hline Hemorrhage & $22(36.1)$ \\
\hline Headaches & $14(23.0)$ \\
\hline Seizures & $13(21.3)$ \\
\hline Other & $9(14.8)$ \\
\hline Incidental & $3(4.9)$ \\
\hline \multicolumn{2}{|l|}{ Lesion type } \\
\hline AVM & $51(83.6)$ \\
\hline AVF & $10(16.4)$ \\
\hline \multicolumn{2}{|l|}{ AVM location, $n=51$} \\
\hline Frontal & $15(29.4)$ \\
\hline Temporal & $13(25.5)$ \\
\hline Cerebellar & $10(19.6)$ \\
\hline Parietal & $6(11.8)$ \\
\hline Occipital & $5(9.8)$ \\
\hline Thalamus & $2(3.9)$ \\
\hline AVM size, mean $\pm S D$ (range) in $\mathrm{mm}$ & $30.6 \pm 13.2(8-76)$ \\
\hline \multicolumn{2}{|l|}{ Spetzler-Martin grade (I-V) } \\
\hline Mean \pm SD & $2.4 \pm 0.9$ \\
\hline Median & 2 \\
\hline Perinidal/intranidal aneurysm, $n=51$ & $11(21.6)$ \\
\hline Resection, $n=51$ & $39(76.5)$ \\
\hline Radiosurgery & $7(11.5)$ \\
\hline Embolization only & $14(22.9)$ \\
\hline \multicolumn{2}{|l|}{ Modified Rankin Scale score† } \\
\hline 0 & $25(41.0)$ \\
\hline 1 & 22 (36.1) \\
\hline 2 & $6(9.8)$ \\
\hline 3 & $3(4.9)$ \\
\hline 4 & $1(1.6)$ \\
\hline 5 & $1(1.6)$ \\
\hline 6 & $3(4.9)$ \\
\hline
\end{tabular}

Values are number (\%) unless indicated otherwise.

* Percentages total $>100 \%$ due to rounding.

$\dagger$ Percentages total $<100 \%$ due to rounding.

success rate (172/177 pedicles [97.2\%]). Infrequently, other microcatheters were also used $(33 / 210[15.7 \%])$ in an embolization session (Table 2). The Apollo microcatheter was used in 79 embolization sessions. For the 61 patients, most procedures were performed during a single embolization session (50/61 [82\%]), and most patients had 1 or 2 pedicles embolized per session $477 / 79$ embolization sessions [59.5\%]). Onyx was the embolysate of choice for $128(74.4 \%)$ of the 172 successful Apollo catheteriza- 
TABLE 2. Descriptive analysis of the endovascular treatment of AVMs or AVFs in 61 patients

\begin{tabular}{|c|c|}
\hline Variable & No. $(\%)$ \\
\hline Catheter used in catheterizations & 210 \\
\hline Apollo & $177(84.3)$ \\
\hline Successful catheterizations & $172(97.2)$ \\
\hline Failed catheterizations & $5(2.8)$ \\
\hline Echelon 10 & $20(9.5)$ \\
\hline Excelsior SL-10 & $8(3.8)$ \\
\hline Marathon & $4(1.9)$ \\
\hline Headway Duo & $1(0.5)$ \\
\hline Embolization sessions per patient* & 61 \\
\hline 1 & $50(82.0)$ \\
\hline 2 & $7(11.5)$ \\
\hline 3 & $2(3.3)$ \\
\hline$\geq 4$ & $2(3.3)$ \\
\hline Pedicles embolized per procedure $†$ & 79 \\
\hline 1 & $22(27.8)$ \\
\hline 2 & $25(31.6)$ \\
\hline 3 & $17(21.5)$ \\
\hline$\geq 4$ & $15(19.1)$ \\
\hline $\begin{array}{l}\text { Liquid embolic agent used in Apollo microcatheteriza- } \\
\text { tions* }\end{array}$ & 172 \\
\hline Onyx-18 & $103(60.0)$ \\
\hline Onyx-34 & $25(14.5)$ \\
\hline NBCA & $44(25.6)$ \\
\hline Degree of angiographic obliteration achieved & 61 \\
\hline$<50 \%$ & $14(23.0)$ \\
\hline $50-74 \%$ & $19(31.1)$ \\
\hline $75-94 \%$ & $17(27.9)$ \\
\hline $95-100 \%$ & $11(18.0)$ \\
\hline Apollo detachment status & 172 \\
\hline Detachment present & $33(19.2)$ \\
\hline Detachment absent & $127(73.8)$ \\
\hline Detachment undetermined & $12(7.0)$ \\
\hline Retained microcatheters & 0 \\
\hline Endovascular morbidity per procedure, $n=79$ & $5(6.3)$ \\
\hline Endovascular morbidity per catheterization, $n=172$ & $5(2.9)$ \\
\hline Apollo-related morbidity & 0 \\
\hline Endovascular mortality, $n=79$ & $1(1.3)$ \\
\hline Apollo-related mortality & 0 \\
\hline
\end{tabular}

tions. Angiographic obliteration of $\geq 75 \%$ was achieved in $28(45.9 \%)$ of 61 patients. The Apollo microcatheter tip was successfully detached in $33(19.2 \%)$ of 172 catheterizations, and it was retrieved intact in 127 (73.8\%). In 12 catheterizations $(7 \%)$, we were unable to determine the detachment status despite chart and angiography imaging review. Microcatheter tip detachment rates were similar for AVMs and AVFs; detachment was successful in 30 (20\%) of 150 AVM catheterizations and in $3(30 \%)$ of 10 AVF catheterizations $(\mathrm{p}=0.43)$.

On univariate analysis, microcatheter tip detachment ( $\mathrm{p}$ $=0.12)$, single embolized pedicles $(\mathrm{p}=0.12)$, and smaller nidus diameter $(\mathrm{p}=0.17)$ were independent variables that appeared to be associated with the likelihood of high ( $>$ $90 \%)$ AVM obliteration rates $(\mathrm{p}<0.20)$. The number of embolization sessions did not appear to correlate with angiographic obliteration. On multivariate analysis, the detachment of a microcatheter tip was the only independent variable with a positive association with high AVM obliteration rates (OR 9.5, 95\% CI 1.5-98; $\mathrm{p}=0.03$ ).

The Apollo microcatheter was successfully retrieved in all cases, and no instances of catheter entrapment were observed. No inadvertent tip detachment, microcatheter breakage, or perforation was observed. Endovascular-related morbidity occurred in 5 patients. In 3 patients with transient complications, there was 1 occurrence each of asymptomatic Onyx pulmonary embolism, proximal vertebral artery guide catheter dissection with an asymptomatic infarct, and transient diplopia after a cerebellar AVM embolization. In 2 patients with permanent complications, there was 1 occurrence each of brainstem infarction and arterial feeder microcatheter perforation with symptomatic intracerebral hemorrhage (using a Marathon microcatheter [Covidien/Medtronic]). Thus, the rate of transient endovascular-related morbidity was 3.8\% (3/79) and the rate of permanent morbidity was $2.5 \%(2 / 79)$ per procedure, with an overall morbidity per procedure of $6.3 \%(5 / 79)$. No complication was directly associated with selection of the Apollo microcatheter. Three $(4.9 \%)$ of 61 patients who were hospitalized died during their hospital stay. Two of these patients died of complications related to the initial hemorrhage at presentation. One patient died of an endovascular-related complication, for a per-procedure mortality rate of $1.3 \%(1 / 79)$. This patient was a 40 -year-old man with a ruptured AVM in the right cerebellar hemisphere. During attempts to obtain distal microcatheter positioning into the right anterior inferior cerebellar artery for Onyx embolization of the AVM, he suffered a fatal intraoperative hemorrhage from a flow-related aneurysm.

\section{Discussion}

Detachable-tip microcatheters are intended to reduce the risk of catheter entrapment during the deployment of liquid embolysate. The technical principle of a detachabletip microcatheter for embolization of intracranial AVMs is not new; the first microcatheter with this feature (Sonic flow-directed, braided microcatheter) was released in Europe in 2006, and case reports of its successful application for Onyx ${ }^{34}$ and $\mathrm{NBCA}^{22}$ embolization were first reported in 2008. Several European centers have published their initial experiences with this device..$^{20,22,33,34,36}$ However, experience with this device outside Europe is limited, and the microcatheter has not received FDA approval as of the time of the writing of this paper.

Since the approval of the Apollo detachable-tip microcatheter by the FDA in 2014, its successful use has been reported in only a few small case series. ${ }^{1,2,12,13,15,24,31}$ It has 2 radiopaque markers: one at the microcatheter distal tip 
TABLE 3. Published case series on the use of detachable-tip microcatheters (Sonic, Apollo) for endovascular treatment of intracranial vascular lesions (2008-2016)

\begin{tabular}{|c|c|c|c|c|c|c|c|c|c|}
\hline Authors \& Year & $\begin{array}{l}\text { No. of } \\
\text { Pts }\end{array}$ & Lesion Type & $\begin{array}{c}\text { No. of } \\
\text { Pedicles }\end{array}$ & $\begin{array}{l}\text { Catheter } \\
\text { Type }\end{array}$ & Detachment & Embolysate & $\begin{array}{c}\text { Obliteration, } \\
\%\end{array}$ & $\begin{array}{c}\text { DTM } \\
\text { Morbidity, \% }\end{array}$ & $\begin{array}{c}\text { DTM } \\
\text { Mortality, \% }\end{array}$ \\
\hline Öztürk et al., 2008 & 1 & AVM & 1 & Sonic & No & NBCA & 50 & 0 & 0 \\
\hline Tahon et al., 2008 & 1 & AVF & 1 & Sonic & Yes & Onyx & 100 & 0 & 0 \\
\hline Maimon et al., 2010 & $43^{*}$ & AVM & 93 & Sonic & NA & Onyx & NA & 3.2 & 0 \\
\hline van Rooij et al., 2012 & $24^{*}$ & AVM & NA & Sonic & NA & Onyx & 100 & NA & NA \\
\hline Strauss et al., 2013 & $92^{*}$ & AVM & 233 & Sonic & NA & Onyx & NA & 3.4 & NA \\
\hline Altschul et al., 2014 & 11 & $\begin{array}{l}\text { AVM, AVF, vein of } \\
\text { Galen }\end{array}$ & 27 & Apollo & Yes $(26 \%)$ & $\begin{array}{l}\text { NBCA (16), } \\
\text { Onyx (11) }\end{array}$ & NA & 0 & 0 \\
\hline Chapot et al., 2014 & 25 & AVM & NA & Sonic & NA & Onyx & NA & 0 & 0 \\
\hline Herial et al., 2014 & 1 & AVM & 2 & Apollo & Yes (50\%) & Onyx & 80 & 0 & 0 \\
\hline Herial et al., 2015 & 3 & AVM, AVF & 7 & Apollo & Yes (43\%) & Onyx & $75-100$ & 0 & 0 \\
\hline Abud et al., 2016 & 27 & AVM, AVF, tumors & NA & Apollo & NA & Onyx & NA & 0 & 0 \\
\hline Limbucci et al., 2016 & 1 & Maxillary AVM & 1 & Apollo & Yes & Onyx & 100 & NA & NA \\
\hline Singla et al., 2016 & 1 & AVF & 1 & Apollo & Yes & Onyx & NA & $\begin{array}{l}\text { Apollo tip scalp } \\
\text { extrusion }\end{array}$ & NA \\
\hline
\end{tabular}

DTM = detachable-tip microcatheter; NA = not available; pts = patients.

* Number of patients treated with the Sonic detachable-tip microcatheter is unknown.

and another, more proximal one at the detachment zone. It has a stainless steel proximal coil for structural support and nitinol distal braiding that provides high kink resistance. It is available with distal tip lengths of $15 \mathrm{~mm}$ and $30 \mathrm{~mm}$. The catheter has a typical proximal outer diameter of $2.7 \mathrm{Fr}$, a distal outer diameter of $1.5 \mathrm{Fr}$, an inner diameter of 0.013 inches, and a total length of $165 \mathrm{~cm} .^{12}$ According to the manufacturer, a thumb pressure of 0.16 $\mathrm{ml} / \mathrm{min}$ is recommended as the injection rate (maximum $0.3 \mathrm{ml} / \mathrm{min}$ ) for the Onyx liquid embolic system. Successful tip detachment should occur under atraumatic forces of approximately $33 \mathrm{~g}$. The force needed for microcatheter extraction is variable, depending on factors such as vessel tortuosity, amount of reflux, and proximal access support. Traction of 3-5 cm might be observed before microcatheter withdrawal. In some cases, it can be verified by increasing distances between the proximal and distal markers under direct fluoroscopic visualization..$^{2}$ Prolonged injection pauses ( $>2$ minutes) should be avoided to minimize the possibility of microcatheter occlusion.

The long-term risks associated with a retained catheter are not well known. It may become fixed to the arterial wall or it may be mobile, which can result in delayed thromboembolic complications. ${ }^{24}$ Although the newer hydrophilic coated microcatheters have improved navigation and safety, the theoretical concern for retained microcatheters remains a limiting factor in embolization with either NBCA or Onyx. ${ }^{2}$ The feared risk of microcatheter retention or target vessel rupture during microcatheter retrieval limits the amount of embolysate used with each embolization. Detachable-tip microcatheters have been developed to circumvent these limitations. They allow for more controlled and longer injections, and for better lesion penetration with minimized risk of microcatheter retention. Our recent systematic review of the endovascular literature reported a $3.4 \%$ per patient incidence of microcatheter retention after embolization of intracranial AVMs. ${ }^{8}$

Despite the advantages of the Apollo microcatheter, neurointerventionalists should be cognizant of some important technical nuances associated with its use. The distal tip is very fragile, and it should be handled with care to avoid unintended premature detachment. The Apollo introducer sheath should always be used to prevent inadvertent microcatheter tip damage during introduction into the guide catheter or intermediate catheters. The integrity of the microcatheter tip should be verified before reinsertion of the guidewire and before each embolysate injection to prevent vascular damage or unintended delivery of embolysate through a fractured detachment zone. Review of the integrity of the tip can typically be achieved with contrast injection and angiographic visualization of contrast from the catheter tip while viewing the entire distal section of the catheter. Unlike standard dimethyl sulfoxide (DMSO)-compatible microcatheters, the Apollo catheter should not be repositioned after the start of Onyx injections; one should also not attempt to clear an "Onyxclogged" device by high-pressure infusion. ${ }^{13}$

The current study represents the largest case series published to date on the safety and application of the Apollo detachable-tip microcatheter for the endovascular treatment of intracranial AVMs and AVFs (Table 3)., ${ }^{1,2,4}$ $12,13,15,20,22,31,33,34,36$ In this study, the successful catheterization rate was high $(97.2 \%, 172 / 177)$, which underscores the adequate navigability of the microcatheter even in small, distal arterial branches that are difficult to navigate, despite its soft distal tip. There were no cases of unintended tip detachment of retained microcatheters in more than 170 catheterizations. Despite the fact that the majority of patients in this series underwent embolization as an adjunctive therapy to radiosurgery or microsurgery, $75 \%$ or more of the lesion volume was successfully embolized in 

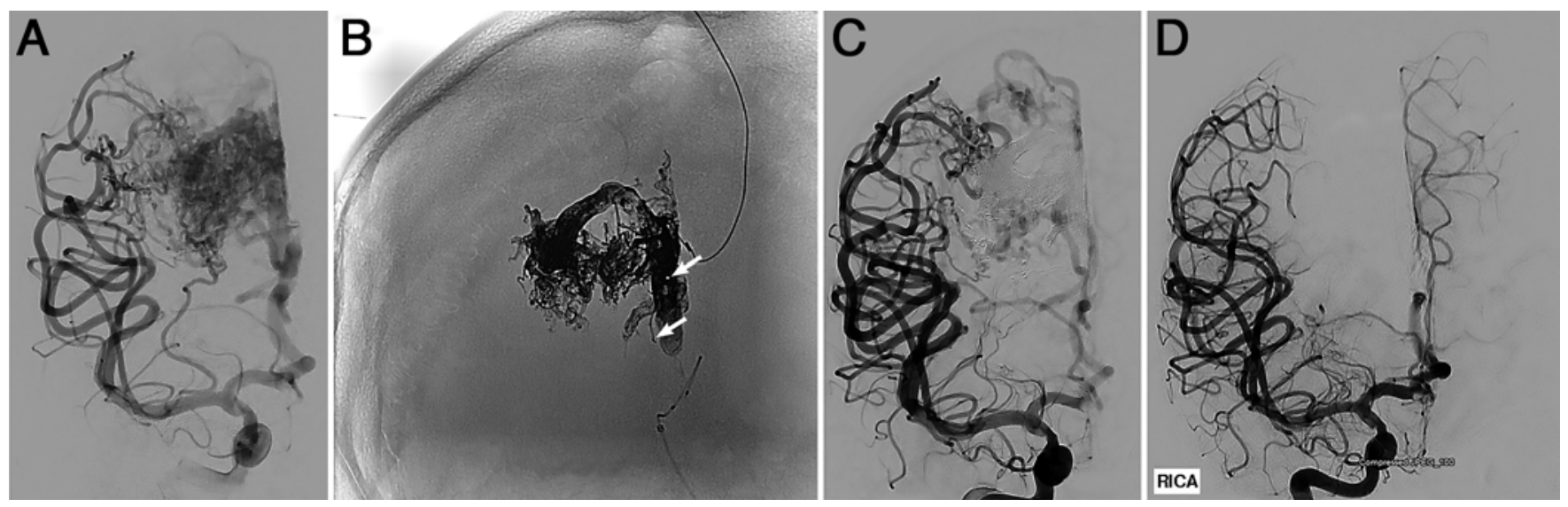

FIG. 2. A: Anteroposterior (AP) right internal carotid artery (ICA) subtracted angiogram of a Spetzler-Martin grade IV unruptured AVM in the right frontal region in a patient who presented with seizures refractory to medical therapy. This image demonstrates an arterial supply from the right pericallosal artery, the right callosomarginal artery, the right parietal cortical middle cerebral artery branches, and a lateral lenticulostriate artery. B: A large Onyx embolysate cast is visible in this AP native fluoroscopic image. An occipital neuromonitoring lead is visible at the medial aspect of the Onyx cast, and an Apollo microcatheter is visible in the inferomedial corner within an intermediate catheter (note the 2 radiopaque markers defining the Apollo detachment zone and the Apollo distal tip). A previously detached Apollo tip is visible on the inferior aspect of the Onyx cast (arrows). C: Final postembolization AP right ICA subtracted angiogram demonstrating $60 \%$ angiographic obliteration. This patient underwent 4 endovascular sessions, with 14 embolized pedicles (13 using Apollo microcatheters); NBCA, Onyx-18, and Onyx-34 were used as liquid embolysates.

D: Postoperative follow-up AP right ICA subtracted angiogram demonstrating complete resection.

nearly one-half of the patients (Fig. 2). More importantly, the high obliteration rate was achieved with a single embolization session in $82 \%(50 / 61)$ of the patients, which indirectly emphasizes the more aggressive nature of embolization using detachable-tip microcatheters. On multivariate analysis, tip detachment showed a strong correlation with high AVM obliteration rates; patients in whom more than $90 \%$ of their AVMs were obliterated were 9.5 times more likely to present with at least one Apollo tip detachment. Often, the use of a detachable-tip microcatheter allowed for more aggressive and consistent embolization (Fig. 3).
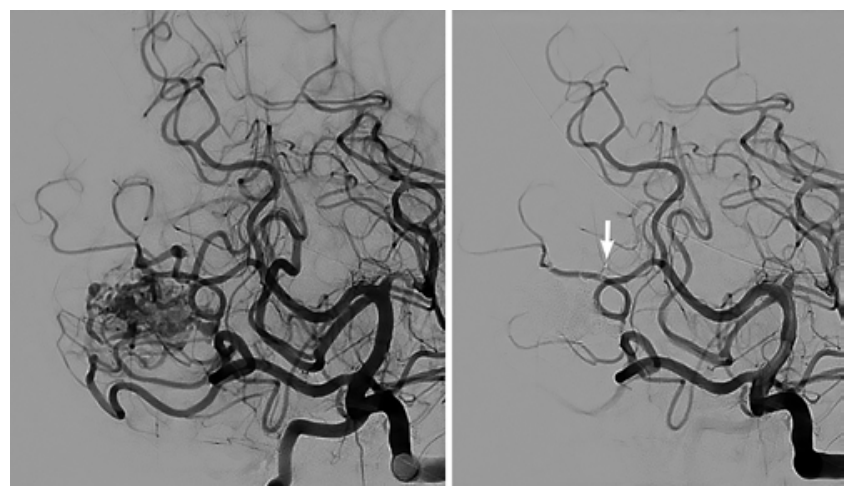

FIG. 3. Left: A Spetzler-Martin grade II AVM in the right cerebellar hemisphere in a patient who presented with hemorrhage. The arterial supply to the AVM was primarily through the right anterior inferior cerebellar artery and the right superior cerebellar artery. The AVM was preoperatively embolized using an Apollo microcatheter and Onyx-18 through a single pedicle off the right anterior inferior cerebellar artery. Right: Postembolization oblique subtracted angiogram revealing complete angiographic obliteration. Note the subtracted image of the detached microcatheter distal tip (arrow).
In some cases, the Apollo microcatheter was used in combination with a DMSO-compatible standard microcatheter that was positioned proximally on the same arterial pedicle, for an efficient, modified pressure cooker technique. ${ }^{4}$ The incidence of endovascular-related morbidity was low (transient and permanent morbidity rates of 3.8\% [3/79] and $2.5 \%$ [2/79], respectively) compared with our recently published institutional experience of endovascular treatment of cerebral AVMs in the pre-Apollo era (transient and permanent morbidity, $1.8 \%$ and $9.6 \%$, respectively). ${ }^{5}$ Our complication rate also compares favorably with the rates in other institutional multimodality embolization series in adults and children, which range from $6.7 \%$ to $11 \% .^{3,16,18}$ It is important to emphasize that none of the complications observed in the current study were directly related to use of the Apollo microcatheter or unintended premature tip detachment. One hemorrhagic complication occurred due to rupture of a flow-related aneurysm during distal catheterization using an Apollo microcatheter; however, the aneurysm rupture had no direct correlation with the Apollo microcatheter detachable-tip features.

AVM complexity in this series is similar to that reported in other contemporary embolization series, with a mean Spetzler-Martin grade of 2.4. ${ }^{3,6}$ In this series, a greater propensity for multimodality treatment was evident, with nearly $80 \%$ of patients undergoing microsurgery or radiosurgery, compared with $9 \%$ in the 2014 report by Baharvahdat et al. ${ }^{3}$ Several studies that have recently reported high angiographic cure rates using Onyx embolization to treat intracranial AVMs have primarily been based on the use of detachable-tip microcatheters. ${ }^{1,6,20,29,36}$ Comparatively, the results from the current study also appear to be congruent with reports from some of the largest published studies on Onyx embolization of brain AVMs (Table 4)..$^{10,11,14,17,19,21,23,25-28,30,32,35,37-40}$ 
TABLE 4. Literature review and comparative analysis of large case series of Onyx embolization of brain AVMs without the use of a detachable-tip microcatheter (2003-2017)

\begin{tabular}{|c|c|c|c|c|c|c|c|c|c|c|c|c|c|c|}
\hline \multirow{2}{*}{$\begin{array}{l}\text { Authors \& } \\
\quad \text { Year }\end{array}$} & \multirow{2}{*}{$\begin{array}{c}\text { No. } \\
\text { of } \\
\text { Pts }\end{array}$} & \multirow{2}{*}{$\begin{array}{l}\text { Mean } \\
\text { Age, } \\
\text { Yrs }\end{array}$} & \multirow{2}{*}{$\begin{array}{c}\text { Mean } \\
\text { AVM } \\
\text { Size, } \\
\mathrm{mm}\end{array}$} & \multicolumn{5}{|c|}{$\begin{array}{l}\text { Spetzler-Martin } \\
\text { Grade, } \%\end{array}$} & \multirow[b]{2}{*}{ AVM Vol Reduction (n) } & \multirow{2}{*}{$\begin{array}{l}\text { Endo- } \\
\text { vascular } \\
\text { Cure, \% }\end{array}$} & \multirow{2}{*}{$\begin{array}{c}\text { Retained } \\
\text { Microcatheter, } \\
n\end{array}$} & \multicolumn{2}{|c|}{$\begin{array}{l}\text { Morbidity, } \\
\%\end{array}$} & \multirow{2}{*}{$\begin{array}{c}\text { - Mortality } \\
\%\end{array}$} \\
\hline & & & & I & $\|$ & III & IV & V & & & & Minor & Major & \\
\hline FDA trial ${ }^{35}$ & 46 & 40.3 & 26.30 & 10.9 & 43.5 & 26.1 & 19.6 & 0.0 & NA & NA & NA & 30.4 & 23.9 & 4.3 \\
\hline $\begin{array}{l}\text { Pérez-Higuer- } \\
\text { as et al., } \\
2005\end{array}$ & 45 & 35 & NA & & & & & & $\begin{array}{l}<60 \%(4),>80 \%(18),>90 \% \\
\quad(15), 100 \%(8)\end{array}$ & 22.2 & 2 & 11.1 & 15.6 & 2.2 \\
\hline $\begin{array}{l}\text { Song et al., } \\
\quad 2005\end{array}$ & 50 & 28 & NA & & & & & & $\begin{array}{l}\text { Subtotal or majority em- } \\
\text { bolization (25); NA (15), } \\
100 \%(10)\end{array}$ & 20.0 & 3 & 12.0 & 10.0 & 0.0 \\
\hline $\begin{array}{l}\text { Mounayer et } \\
\text { al., } 2007\end{array}$ & 94 & 32 & NA & 4.3 & 37.2 & 40.4 & 17.0 & 1.1 & NA & 27.7 & 4 & 7.4 & 3.2 & 1.1 \\
\hline $\begin{array}{l}\text { Weber et al., } \\
2007^{38}\end{array}$ & 47 & 36 & 34.00 & 19.1 & 34.0 & 21.3 & 23.4 & 2.1 & $\begin{array}{l}<50 \%(2), 50-74 \%(7), \\
\quad 75-89 \%(12), 90-99 \% \\
\quad(26)\end{array}$ & 12.8 & 4 & 19.1 & 8.5 & 0.0 \\
\hline $\begin{array}{l}\text { Katsaridis et } \\
\text { al., } 2008\end{array}$ & 101 & 38.8 & NA & 6.9 & 17.8 & 38.6 & 32.7 & 4.0 & $\begin{array}{l}<50 \%(6),>80 \%(18), 100 \% \\
\quad(28)\end{array}$ & 27.7 & 1 & 6.9 & 11.9 & 3.0 \\
\hline $\begin{array}{l}\text { Gao et al., } \\
2009\end{array}$ & 115 & 29 & NA & 8.7 & 24.3 & 37.4 & 26.1 & 3.5 & $\begin{array}{l}<80 \%(30), 80-99 \%(35) \\
\quad 100 \%(23)\end{array}$ & 20.0 & 5 & 11.3 & 4.3 & 0.9 \\
\hline $\begin{array}{l}\text { Loh \& Duck- } \\
\text { wiler, } 2010\end{array}$ & 54 & 40 & 26.00 & 14.8 & 38.9 & 24.1 & 22.2 & 0.0 & $>50 \%(48)$ & NA & 0 & 3.7 & 9.3 & 3.7 \\
\hline Lv et al., 2011 & 147 & 27.5 & 40.00 & 3.4 & 13.6 & 36.7 & 29.9 & 16.3 & Mean $63 \%$, range $10-100 \%$ & 19.7 & 0 & 1.4 & 1.4 & 0.0 \\
\hline $\begin{array}{l}\text { Saatci et al., } \\
2011\end{array}$ & 350 & 34 & NA & 14.9 & 30.3 & 28.3 & 19.7 & 6.9 & $100 \%(179)$ & 51.1 & 28 & 3.7 & 7.1 & 1.4 \\
\hline Xu et al., 2011 & 86 & 30.3 & 35.00 & 3.5 & 15.1 & 52.3 & 22.1 & 7.0 & $\begin{array}{l}<50 \%(6), 50-69 \%(10) \\
70-79 \%(10), 80-89 \% \\
\quad(21), 90-99 \%(23), 100 \% \\
(16)\end{array}$ & 18.6 & 3 & 3.5 & 5.8 & 1.2 \\
\hline $\begin{array}{l}\text { Pierot et al., } \\
2013\end{array}$ & 117 & 42.6 & NA & 17.1 & 37.6 & 23.9 & 20.5 & 0.9 & $\begin{array}{l}<50 \%(17), 50-74 \%(32) \\
\quad 75-99 \%(39), 100 \%(27)\end{array}$ & 23.1 & 0 & 16.2 & 12.0 & 4.3 \\
\hline $\begin{array}{l}\text { All studies ( } \mathrm{n} \\
\quad=18)\end{array}$ & 1610 & 35.3 & 34.95 & 16.7 & 24.3 & 31.9 & 22.1 & 5.0 & NA & 20.3 & $73(4.5 \%)$ & 8.2 & 8.8 & 1.6 \\
\hline $\begin{array}{l}\text { Present } \\
\text { study* }\end{array}$ & 51 & 36.83 & 30.60 & 9.0 & 18.0 & 18.0 & 4.0 & 1.0 & $\begin{array}{l}<50 \%(14), 50-74 \%(16), \\
\quad 75-99 \%(16), 100 \%(5)\end{array}$ & 9.8 & 0 & 8.7 & 2.9 & 2.0 \\
\hline
\end{tabular}

* AVM patients only. 
Some financial aspects should be considered by the neurointerventionalist when deciding between the use of a standard Onyx-compatible microcatheter and the Apollo detachable-tip microcatheter. Despite the theoretical advantage of the Apollo in reducing the probability of a retained catheter and allowing for more aggressive embolization through a single pedicle access, the price difference between these microcatheters can be substantial. Commercial data obtained from the manufacturer show that the cost of the Apollo microcatheter could be almost twice the price of the Marathon flow-guided microcatheter (\$2145 vs \$1130; personal communication). In specific situations, this cost difference can be offset by potential decreases in the number of microcatheters exchanged and in the number of arterial pedicles catheterized, both of which are allowed by a higher tolerance to Onyx associated with a detachable-tip mechanism.

The possibility of microcatheter retention raises potential complications that are different from those of other catheter designs. Few reports have been published on the safety of this catheter. The long-term consequences of tip retention are still poorly understood. Tip retention would be especially problematic in cases in which embolization was used as monotherapy or associated with stereotactic radiosurgery and surgical retrieval of a catheter tip would not be possible. Potential complications of tip retention may be elucidated by an ongoing postmarket safety study to evaluate the safety of the Apollo delivery microcatheter for brain AVM embolization procedures (clinical trial no. NCT02378883). This postmarket registry, with an estimated enrollment of 161 patients, has not yet released preliminary data. A similar clinical trial is evaluating the safety of the Apollo microcatheter in pediatric patients (clinical trial no. NCT02085278).

The current study has a number of limitations. The retrospective nature of the data collection introduces natural selection bias inherent to this type of study. The Apollo catheter was not necessarily used in isolation; given the retrospective nature of this study, it is not possible to determine which adjunctive catheters were used due to perceived or actual navigation limitations of the Apollo itself. In 7\% of the Apollo microcatheterizations, the tip detachment status could not be determined by operative report or angiographic imaging review. The heterogeneity of the studied groups is accentuated by the multiinstitutional nature of the data collection. Finally, no matched control groups with similar lesions treated with standard DMSOcompatible microcatheters are available for comparison, and the pre-Apollo data presented in this article derive exclusively from a systematic review of the literature.

\section{Conclusions}

Use of the Apollo detachable-tip microcatheter for embolization of AVMs and AVFs is associated with high rates of successful catheterization and obliteration and low rates of morbidity and mortality. This microcatheter system allows the neurointerventionalist the option of a more aggressive embolization, with prolonged injection time and higher tolerance for Onyx or NBCA reflux. In the current study, the Apollo microcatheter was retrieved in all cases, even after prolonged injections in distal branch pedicles, often with significant reflux. In multivariate analysis, tip detachment was significantly associated with higher AVM or AVF obliteration rates. The current study represents the largest case series on the use of the Apollo microcatheter for neurointerventional procedures. Further studies are needed to evaluate the long-term safety of retained detachable tips in patients who do not undergo adjuvant resection.

\section{Acknowledgments}

We thank the staff of Neuroscience Publications at Barrow Neurological Institute for invaluable and essential assistance with the preparation of this manuscript.

\section{References}

1. Abud DG, de Castro-Afonso LH, Nakiri GS, Monsignore LM, Colli BO: Modified pressure cooker technique: an easier way to control Onyx reflux. J Neuroradiol 43:218-222, 2016

2. Altschul D, Paramasivam S, Ortega-Gutierrez S, Fifi JT, Berenstein A: Safety and efficacy using a detachable tip microcatheter in the embolization of pediatric arteriovenous malformations. Childs Nerv Syst 30:1099-1107, 2014

3. Baharvahdat H, Blanc R, Termechi R, Pistocchi S, Bartolini $\mathrm{B}$, Redjem H, et al: Hemorrhagic complications after endovascular treatment of cerebral arteriovenous malformations. AJNR Am J Neuroradiol 35:978-983, 2014

4. Chapot R, Stracke P, Velasco A, Nordmeyer H, Heddier M, Stauder M, et al: The pressure cooker technique for the treatment of brain AVMs. J Neuroradiol 41:87-91, 2014

5. Crowley RW, Ducruet AF, Kalani MY, Kim LJ, Albuquerque FC, McDougall CG: Neurological morbidity and mortality associated with the endovascular treatment of cerebral arteriovenous malformations before and during the Onyx era. $\mathbf{J}$ Neurosurg 122:1492-1497, 2015

6. de Castro-Afonso LH, Nakiri GS, Oliveira RS, Santos MV, Santos ACD, Machado HR, et al: Curative embolization of pediatric intracranial arteriovenous malformations using Onyx: the role of new embolization techniques on patient outcomes. Neuroradiology 58:585-594, 2016

7. Farrell B, Godwin J, Richards S, Warlow C: The United Kingdom transient ischaemic attack (UK-TIA) aspirin trial: final results. J Neurol Neurosurg Psychiatry 54:1044-1054, 1991

8. Flores BC, Gross BA, Albuquerque FC: Endovascular treatment of arteriovenous malformations using ethylene vinyl alcohol copolymer, in Prestigiacomo CJ, Gandhi CD (eds): Cerebrovascular and Endovascular Neurosurgery. New York: Springer, 2018

9. Flores BC, Klinger DR, Rickert KL, Barnett SL, Welch BG, White JA, et al: Management of intracranial aneurysms associated with arteriovenous malformations. Neurosurg Focus 37(3):E11, 2014

10. Gao K, Yang XJ, Mu SQ, Li YX, Zhang YP, Lü M, et al: Embolization of brain arteriovenous malformations with ethylene vinyl alcohol copolymer: technical aspects. Chin Med J (Engl) 122:1851-1856, 2009

11. Hauck EF, Welch BG, White JA, Purdy PD, Pride LG, Samson D: Preoperative embolization of cerebral arteriovenous malformations with Onyx. AJNR Am J Neuroradiol 30:492-495, 2009

12. Herial NA, Khan AA, Sherr GT, Qureshi MH, Suri MF, Qureshi AI: Detachable-tip microcatheters for liquid embolization of brain arteriovenous malformations and fistulas: a United States single-center experience. Neurosurgery 11 (Suppl 3):404-411, 2015

13. Herial NA, Khan AA, Suri MF, Sherr GT, Qureshi AI: Liq- 
uid embolization of brain arteriovenous malformation using novel detachable tip micro catheter: a technical report. J Vasc Interv Neurol 7:64-68, 2014

14. Katsaridis V, Papagiannaki C, Aimar E: Curative embolization of cerebral arteriovenous malformations (AVMs) with Onyx in 101 patients. Neuroradiology 50:589-597, 2008

15. Limbucci N, Spinelli G, Nappini S, Renieri L, Consoli A, Rosi A, et al: Curative transvenous Onyx embolization of a maxillary arteriovenous malformation in a child: report of a new technique. J Craniofac Surg 27:e217-e219, 2016

16. Lin N, Smith ER, Scott RM, Orbach DB: Safety of neuroangiography and embolization in children: complication analysis of 697 consecutive procedures in 394 patients. J Neurosurg Pediatr 16:432-438, 2015

17. Loh Y, Duckwiler GR: A prospective, multicenter, randomized trial of the Onyx liquid embolic system and N-butyl cyanoacrylate embolization of cerebral arteriovenous malformations. Clinical article. J Neurosurg 113:733-741, 2010

18. Lopes DK, Moftakhar R, Straus D, Munich SA, Chaus F, Kaszuba MC: Arteriovenous malformation embocure score: AVMES. J Neurointerv Surg 8:685-691, 2016

19. Lv X, Wu Z, Jiang C, Li Y, Yang X, Zhang Y, et al: Complication risk of endovascular embolization for cerebral arteriovenous malformation. Eur J Radiol 80:776-779, 2011

20. Maimon S, Strauss I, Frolov V, Margalit N, Ram Z: Brain arteriovenous malformation treatment using a combination of Onyx and a new detachable tip microcatheter, SONIC: shortterm results. AJNR Am J Neuroradiol 31:947-954, 2010

21. Mounayer C, Hammami N, Piotin M, Spelle L, Benndorf G, Kessler I, et al: Nidal embolization of brain arteriovenous malformations using Onyx in 94 patients. AJNR Am J Neuroradiol 28:518-523, 2007

22. Öztürk MH, Ünal H, Dinç H: Embolization of an AVM with acrylic glue through a new microcatheter with detachable tip: an amazing experience. Neuroradiology 50:903-904, 2008

23. Panagiotopoulos V, Gizewski E, Asgari S, Regel J, Forsting M, Wanke I: Embolization of intracranial arteriovenous malformations with ethylene-vinyl alcohol copolymer (Onyx). AJNR Am J Neuroradiol 30:99-106, 2009

24. Paramasivam S, Altschul D, Ortega-Gutiarrez S, Fifi J, Berenstein A: N-butyl cyanoacrylate embolization using a detachable tip microcatheter: initial experience. J Neurointerv Surg 7:458-461, 2015

25. Pérez-Higueras A, López RR, Tapia DQ: Endovascular treatment of cerebral AVM: our experience with Onyx. Interv Neuroradiol 11 (Suppl 1):141-157, 2005

26. Pierot L, Cognard C, Herbreteau D, Fransen H, van Rooij WJ, Boccardi E, et al: Endovascular treatment of brain arteriovenous malformations using a liquid embolic agent: results of a prospective, multicentre study (BRAVO). Eur Radiol 23:2838-2845, 2013

27. Pierot L, Januel AC, Herbreteau D, Barreau X, Drouineau J, Berge J, et al: Endovascular treatment of brain arteriovenous malformations using Onyx: preliminary results of a prospective multicenter study. Interv Neuroradiol 11 (Suppl 1):159-164, 2005

28. Pierot L, Januel AC, Herbreteau D, Barreau X, Drouineau J, Berge J, et al: Endovascular treatment of brain arteriovenous malformations using Onyx: results of a prospective, multicenter study. J Neuroradiol 36:147-152, 2009

29. Renieri L, Consoli A, Scarpini G, Grazzini G, Nappini S, Mangiafico S: Double arterial catheterization technique for embolization of brain arteriovenous malformations with Onyx. Neurosurgery 72:92-98, 2013
30. Saatci I, Geyik S, Yavuz K, Cekirge HS: Endovascular treatment of brain arteriovenous malformations with prolonged intranidal Onyx injection technique: long-term results in 350 consecutive patients with completed endovascular treatment course. J Neurosurg 115:78-88, 2011

31. Singla A, Fargen KM, Hoh B: Onyx extrusion through the scalp after embolization of dural arteriovenous fistula. J Neurointerv Surg 8:e38, 2016

32. Song D, Leng B, Gu Y, Zhu W, Xu B, Chen X, et al: Clinical analysis of 50 cases of BAVM embolization with Onyx, a novel liquid embolic agent. Interv Neuroradiol 11 (Suppl 1):179-184, 2005

33. Strauss I, Frolov V, Buchbut D, Gonen L, Maimon S: Critical appraisal of endovascular treatment of brain arteriovenous malformation using Onyx in a series of 92 consecutive patients. Acta Neurochir (Wien) 155:611-617, 2013

34. Tahon F, Salkine F, Amsalem Y, Aguettaz P, Lamy B, Turjman F: Dural arteriovenous fistula of the anterior fossa treated with the Onyx liquid embolic system and the Sonic microcatheter. Neuroradiology 50:429-432, 2008

35. US Food and Drug Administration. Catheter Entrapment with the ev3 Onyx Liquid Embolic System: FDA Safety Communication. (https://wayback.archiveit.org/7993/20170722215748/https://www.fda.gov/ MedicalDevices/Safety/AlertsandNotices/ucm310121.htm) [Accessed November 16, 2017]

36. van Rooij WJ, Jacobs S, Sluzewski M, van der Pol B, Beute GN, Sprengers ME: Curative embolization of brain arteriovenous malformations with Onyx: patient selection, embolization technique, and results. AJNR Am J Neuroradiol 33:1299-1304, 2012

37. van Rooij WJ, Sluzewski M, Beute GN: Brain AVM embolization with Onyx. AJNR Am J Neuroradiol 28:172-178, 2007

38. Weber W, Kis B, Siekmann R, Jans P, Laumer R, Kühne D: Preoperative embolization of intracranial arteriovenous malformations with Onyx. Neurosurgery 61:244-254, 2007

39. Weber W, Kis B, Siekmann R, Kuehne D: Endovascular treatment of intracranial arteriovenous malformations with Onyx: technical aspects. AJNR Am J Neuroradiol 28:371377,2007

40. Xu F, Ni W, Liao Y, Gu Y, Xu B, Leng B, et al: Onyx embolization for the treatment of brain arteriovenous malformations. Acta Neurochir (Wien) 153:869-878, 2011

\section{Disclosures}

Dr. Ducruet: consultant for Medtronic.

\section{Author Contributions}

Conception and design: all authors. Acquisition of data: Flores, See. Analysis and interpretation of data: Flores, See. Drafting the article: Flores, See. Critically revising the article: all authors. Reviewed submitted version of manuscript: all authors. Statistical analysis: Flores, See. Study supervision: Albuquerque.

\section{Correspondence}

Felipe C. Albuquerque: c/o Neuroscience Publications, Barrow Neurological Institute, St. Joseph's Hospital and Medical Center, Phoenix, AZ.neuropub@barrowneuro.org. 